\title{
The case for microbicides: A global priority
}

Kathy Attawell

Follow this and additional works at: https://knowledgecommons.popcouncil.org/departments_sbsr-hiv

Part of the Immune System Diseases Commons, International Public Health Commons, Medicine and Health Commons, and the Virus Diseases Commons How does access to this work benefit you? Let us know!

\section{Recommended Citation}

Attawell, Kathy. 2001. "The case for microbicides: A global priority." New York and London: Population Council and International Family Health. 


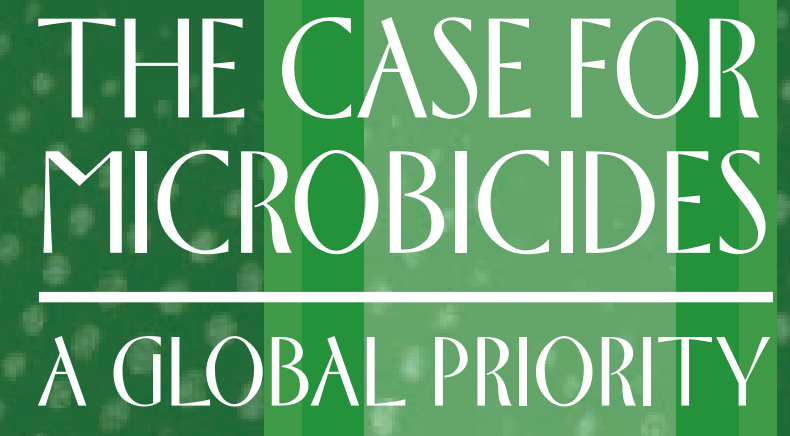

SECOND EDITION 


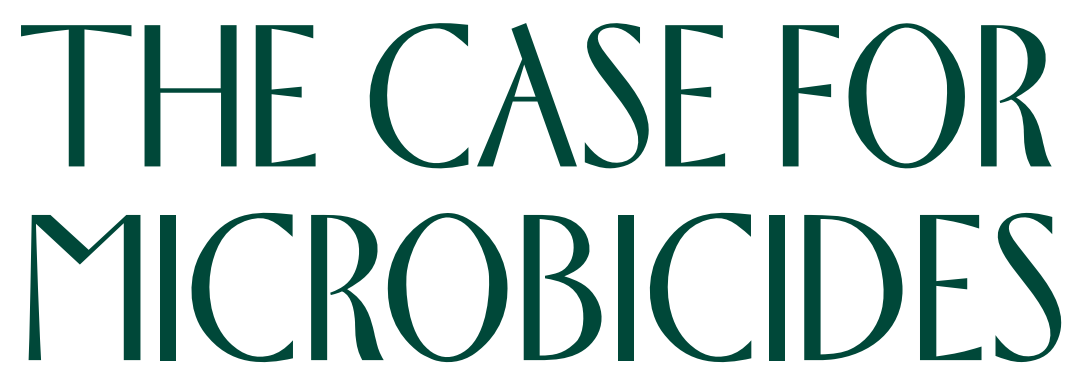

A GLOBAL PRIORITY

SECOND EDITION

(1) Population Council 


\section{(2) Population Council}

One Dag Hammarskjold Plaza

New York, New York 10017

tel 001 212-339-0500

fax $001212-755-6052$

e-mail pubinfo@popcouncil.org

www.popcouncil.org

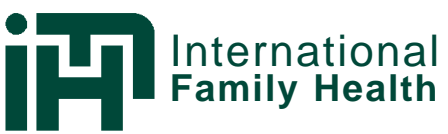

Cityside House, First Floor

40 Adler Street

London E1 1EE, United Kingdom

tel 44 207-247-9944

fax 44 207-247-9224

www.ifh.org.uk

The Population Council is an international, nonprofit, nongovernmental institution that seeks to improve the well-being and reproductive health of current and future generations around the world and to help achieve a humane, equitable, and sustainable balance between people and resources. The Council conducts biomedical, social science, and public health research and helps build research capacities in developing countries. Established in 1952, the Council is governed by an international board of trustees. Its New York headquarters supports a global network of regional and country offices.

International Family Health (IFH), a British non-profit non-governmental organisation governed by a Board of Trustees, was established in 1991 with the aim of improving the sexual and reproductive health of women and men in low-income countries. Strategies to achieve this aim include providing specialist advice, securing financial resources and strengthening local managerial and programming capacity. In practice, IFH provides policy, strategy, project design, implementation, monitoring and evaluation services to governments and multilateral bodies. Working with non-governmental partners in Asia, Africa and Eastern Europe, IFH provides financial, organisational and technical support. IFH also researches and publishes technical papers and reports for dissemination to key decision-makers worldwide.

Copyright @ 2000, 2001 by The Population Council, Inc. and International Family Health

First edition 2000

Second edition 2001

Any part of this report may be copied or adapted to meet local needs without permission from the Population Council or International Family Health, provided that the parts copied are distributed free or at cost (not for profit) and that the source is identified. Any commercial reproduction requires prior permission from the Population Council or International Family Health. The Population Council and International Family Health would appreciate receiving a copy of any materials in which the text is used. 


\section{ACKNOWLEDGEMENTS}

This publication is the product of a year-long, collaborative project to explore ways to raise the profile of microbicides. It involved an extensive literature review and broad consultation with European, US, and developing-country donors, scientists, women's and other activist groups, and organisations with a potential commercial interest in microbicides. Research and writing were done principally by Kathy Attawell, who drew together a wide variety of materials and perspectives coherently and concisely. A draft was reviewed and commented on by participants at a Technical Consultation held in London in April 2000, and also by several other experts in microbicides. This project was directed by Elizabeth McGrory and Susan Crane, in close collaboration with Ros Davies, George Brown, and Susan Perl. Special thanks to Sarah Braunstein and Virginia Kallianes for their work on production. We are grateful to the Department for International Development for supporting this project and publication. The first edition was published in J une 2000.

This revised second edition, published in June 2001, incorporates updated information, mainly about the status of clinical trials and policy efforts. 



\section{MICROBICIDES: A GLOBAL PRIORITY}

\section{Background}

The HIV/AIDS epidemic continues to spread, undermining development, reversing health gains, and exacerbating poverty. Over 36 million people worldwide are living with HIV/AIDS and $95 \%$ of them are in developing countries. Every day more than 16,000 people are newly infected with HIV and current prevention strategies are inadequate to stop the rapid spread of the epidemic. It is estimated that there have been 21.8 million AIDS-related deaths through the end of 2000 . Although research on a preventive vaccine is critically important and moving forward, it will be some time before a vaccine is available and accessible. There is an urgent need to identify additional prevention options.

Women are increasingly affected by HIV/AIDS, representing $47 \%$ of those infected globally and more than $55 \%$ of those infected in sub-Saharan Africa, 30\% in Asia, and 20\% in Europe and the USA. In 2000, almost 5 million adults were newly infected with HIV, of whom nearly half were women. More than $90 \%$ of new infections are spread through unprotected sex, and women, especially young women, are biologically more vulnerable to HIV and other sexually transmitted infections (STIs) than men. Because of gender inequality, condoms, while effective if used correctly and consistently, are simply not a feasible option for many women. The development of a prevention method that women control could save millions of lives.

A microbicide-a product used vaginally to prevent infection-would offer the potential for women to protect themselves and their sexual partners from HIV and other STIs. The prospects for developing microbicides are promising. There is growing consensus that developing a microbicide should be technically feasible, and there has been significant progress in microbicide research and development over the 
last ten years. A number of promising new products are in the pipeline, and findings from market and acceptability research are encouraging. Attention from public-sector and nonprofit agencies and some pharmaceutical companies is increasing, and women in developed and developing countries have expressed high levels of interest in these products.

Most current microbicide research and development is carried out by small biotechnology firms, nongovernmental organisations, and academic institutions, largely supported by public funding. No major pharmaceutical company has made a significant investment in microbicide research and development. Neither the public nor the private sector is investing sufficient resources in microbicide research and development and, at present rates of progress, it is likely to be another decade before safe, effective, and affordable microbicides are available. Reducing this timeframe will require a major increase in investment from a variety of sources, as well as global political commitment, a focused product-oriented strategy, and continued collaboration between scientists, researchers, the public sector, donors, industry, and advocates in developed and developing countries.

This document presents the case for microbicides, discusses recent progress and developments, and notes outstanding challenges and the action required to accelerate research and development and to ensure that products will be made available to those who most need them.

\section{The need for female-controlled methods}

The HIV/AIDS epidemic is driven by social, cultural, and economic gender inequalities that limit women's ability to protect themselves from infection. The main strategies for HIV prevention-condoms, reducing the number of sexual partners, and treatment of reproductive tract infections-are not feasible for many women.

Condom use depends on the consent of male sexual partners and it can be difficult for women to raise the subject 
in relationships where men make sexual decisions and women are economically dependent. Discussing condom use or refusing unsafe sex is particularly difficult in the context of primary partnerships and where women are subject to violence. The female condom has been a good option for some women, but it is not widely available. Reproductive health programmes should make every effort to expand access to and use of the female condom while continuing to build support for the development and rapid introduction of microbicides. Because they are also contraceptives, condoms can be especially problematic where proving fertility is critical to women's status or for couples who wish to have children.

Reducing the number of sexual partners may not be feasible for those women who, because of limited educational and employment opportunities, have few alternatives to exchanging sex for economic survival. In many regions a significant proportion of women are infected with HIV by their husbands. Even when women themselves are monogamous, their partners may not be.

Sexually transmitted infections in women are often asymptomatic, making women less likely to seek treatment, and syndromic management of STIs is less precise in women than in men. The laboratory facilities required to accurately diagnose STIs are also not available in many settings. Even women who do have symptoms of STIs may avoid seeking treatment for fear of stigmatisation. Therefore, many STIs go untreated in women, often with severe health consequences, including increased risk of HIV infection.

Given the limitations of these existing approaches, there is an urgent need to extend the range of prevention methods available, particularly those that women can control. New products, such as microbicides, have the potential to strengthen HIV prevention efforts by allowing women, men, and couples to choose from, and use, a wider range of methods. 


\section{The potential of microbicides}

To be truly female controlled, the ideal microbicide would be effective, safe, acceptable, affordable, colourless, odourless, stable, easy to store and use, available in a variety of preparations, available in contraceptive and noncontraceptive formulations, and available without a prescription. However, because the first microbicide to be developed is unlikely to be an "ideal" product with all these characteristics, the immediate priority is to develop a microbicide that provides protection if used consistently and that will be used by those who need it most.

A microbicide would potentially be effective against a range of STIs in addition to HIV. Unlike condoms, it could be applied in advance of sexual activity and perhaps without requiring the active involvement of sexual partners. Microbicides could increase protection when used in addition to condoms, and could provide a back-up in cases of condom failure. Because consistency of use and coverage is as important as efficacy in determining impact, even a partially effective product could have a significant impact on HIV transmission for individuals and societies where condom use is low. Used rectally, microbicides could also potentially reduce the risk of HIV transmission via anal sex.

While microbicides will have the greatest impact in the developing world in countries most affected by HIV and other STIs, there is also an important potential role for microbicides in reducing STIs in developed countries. As noted earlier, women represent $20 \%$ of people infected with HIV in Europe and the USA. In addition, there is a potentially large and lucrative market for microbicides among men who have sex with men and among women at risk of other STIS, such as chlamydia.

In many cultures and for many couples the importance of having children is a major obstacle to condom use and could also limit use of contraceptive microbicides. Women currently have no option that allows them to conceive while protecting 
them from disease. Therefore, an urgent need exists for noncontraceptive as well as contraceptive formulations.

Microbicides could help protect children and men, as well as women. By reducing the risk of HIV infection in women, microbicides would contribute to a reduction in mother-tochild transmission of HIV. In addition, some microbicides may have the potential to reduce mother-to-child transmission when used for vaginal washing in HIV-positive women prior to delivery. Ideally, microbicides would prevent HIV transmission from women to men and could, therefore, be critical for women with HIV who are unable to disclose their status to sexual partners and serve to protect HIV-negative men from infection. They may also have the potential to protect HIVpositive women from reinfection.

Microbicides offer many potential advantages for increasing a woman's control over her sexual life and for protecting women, men, and children from infection. This potential is moving closer to being realised through the growing efforts of numerous scientists and advocates to develop a safe and effective product and make it available to those most at risk.

\section{CURRENT STATUS AND RECENT DEVELOPMENTS}

\section{Approaches to microbicide development}

Scientists have taken two general approaches to microbicide development: developing and testing new substances, and investigating the potential microbicidal activity of existing spermicidal products.* These approaches focus on microbicide products that act in one of the following ways or that combine different mechanisms in one product:

- Killing or inactivating infectious pathogens-examples include surfactants (detergent-like chemicals) that disrupt the lipid

* Mention of specific products in development does not constitute endorsement. 
membranes of cells and the lipid envelopes (surfaces) of viruses such as HIV and herpes, and certain antibiotics that increase membrane porosity. The surfactants include the existing spermicides nonoxynol-9, octoxynol-9, benzalkonium chloride, menfegol, and novel substances that work in a similar way.

- Blocking attachment to target cells and entry of infectious pathogens-these compounds may prevent infection by blocking the attachment of pathogens to the mucosal surface of target cells. Examples include sulphated and sulphonated polymers such as Carraguard ${ }^{m}$, PRO 2000, and Emmelle.

- Preventing infection from taking hold-examples include antiretroviral agents like PMPA gel, which prevents HIV from replicating in cells, and plantibodies, anti-HIV antibodies genetically engineered from plants that would combat pathogens before infection occurs.

- Enhancing vaginal defence mechanisms-this approach seeks to enhance the vagina's naturally acidic environment and production of hydrogen peroxide, both of which are hostile to pathogens including HIV. Examples include BufferG $\mathrm{Cl}^{\mathrm{m}}$ and Adidform, which help the vagina to maintain natural levels of acidity in the presence of semen, and suppositories containing lactobacillus, which lives normally in the healthy vagina and which produces hydrogen peroxide.

\section{Recent progress in microbicide research and product development}

Microbicide research is increasingly considered a legitimate scientific field. Basic research is growing on issues critical to microbicide development and testing, such as sexual transmission of HIV and other pathogens, vaginal ecology, and appropriate in vitro assays and animal models. The prospects for product development are encouraging and the number of researchers and approaches is growing. Five years ago, only a handful of 


\section{ESTABLISHING MICROBICIDE SAFETY AND EFFECTIVENESS}

PRECLINICAL STUDIES- laboratory and animal studies to assess potential effectiveness against HIV, other STIS, and sperm; toxicity; compatibility with barrier methods; and to predict dosages required, before moving to clinical studies.

CLINICAL STUDIES - to assess safety and effectiveness in humans. Generally have been divided into three phases. Phase I trials are conducted in small numbers (10-50) of women at low risk of sexually transmitted infection, to assess initial safety and acceptability. Phase II trials enroll larger numbers of women - several hundred-potentially at risk of HIV and other STIS, and women with
HIV, to further assess safety and acceptability and to provide preliminary information about efficacy. Phase III trials are conducted in larger numbers - typically hundreds to thousands - of women at risk of HIV and other STIs, to provide information about safety of longer-term use and effectiveness- whether or not the product reduces HIV and other STIs. Given the urgency of the epidemic and the timeframe required for clinical testing, there is growing discussion and exploration of ways to streamline this process through, for example, conducting various safety tests simultaneously, conducting multi-armed studies, and ensuring that data from Phase II and III trials can be pooled.

researchers were working on microbicides. Today, according to the Alliance for Microbicide Development, which monitors product research and development, 38 small biopharmaceutical companies, 28 nonprofit research entities, and six public-sector agencies are working on microbicides. In 1994, a dozen compounds were in the preclinical stages of development, with just eight ready for early Phase I safety trials and none ready for later trials of product efficacy. In contrast, in 2000 over 50 product leads are in development, of which seven are in later-stage clinical trials. Despite this progress in expanding the number of products being developed, they are not moving into expanded clinical testing quickly enough; almost three dozen potential products remain in some stage of preclinical testing. 


\section{MICROBICIDE CLINICAL TRIALS}

- A successful trial with BufferGel" - The Population Council is (produced by Reprotect LLC) was conducted through HIVNET (now the Prevention Trials Network/ HPTN) in four sites in India, Malawi, Thailand, and Zimbabwe. HPTN is also conducting Phase I trials of PRO 2000 (Interneuron) in sexually active HIV-positive and HIV-negative women in two South African and two US sites.

- WHO is planning to collaborate with CONRAD and TOPCAD on a Phase II clinical trial of cellulose sulphate gel, following a successful Phase I trial.

- The UK Medical Research Council and the Institute of Tropical Medicine in Antwerp conducted Phase I trials with PRO 2000 (Interneuron) and Emmelle (ML Laboratories) in London and Antwerp. Data so far show that both products are well tolerated and free of significant side effects in women, and there is evidence of protection in macaques. The London and Antwerp teams will jointly mount Phase II trials with these substances in Ivory Coast and Uganda during 2001. conducting a Phase II trial in South Africa and Thailand with Carraguard", a carrageenan gel, to further assess safety and acceptability; if Carraguard is found to be safe, a Phase III trial will start in early 2002.

- Several Phase III trials with the spermicidal surfactant nonoxynol-9 have so far failed to show any benefit in terms of preventing transmission of HIV, gonorrhoea, or chlamydia in female sex workers. These include a trial of a vaginal contraceptive film (70mg nonoxynol9) carried out by Family Health International in Cameroon, and a trial of a gel formulation of nonoxynol-9 known as COL-1492 (52.5mg nonoxynol-9) sponsored by UNAIDS and carried out in Benin, I vory Coast, South Africa, and Thailand. The data from the four-country trial are still undergoing analysis and the basis of its disappointing outcome is not yet clear. When the data are fully analysed, WHO will convene a consensus meeting to determine future policy recommendations about use of $n-9$. 


\section{Acceptability and demand}

Laboratory and clinical research has been complemented by a growing body of research and literature related to user perspectives on microbicides. Overall, the findings of this research on acceptability, consumer interest, and potential markets for such products are encouraging, suggesting that there is likely to be demand in both developing and developed countries.

Acceptability studies in a range of countries, including Brazil, India, South Africa, Thailand, Uganda, the US, and Zimbabwe, have confirmed the urgent need women feel for a prevention method they control. In these studies women have expressed generally very positive attitudes towards the concept and use of microbicide products in both contraceptive and noncontraceptive formulations. With respect to formulation, although women express preferences for different characteristics and types of microbicide products, proven safety and effectiveness against HIV and other STIs are generally the most important considerations. Initial studies of men in varied settings in Mexico, USA, and Zimbabwe found that they were also generally supportive of the idea of microbicides.

A market survey in the USA, conducted by the Alan Guttmacher Institute, estimated that $\mathbf{1 2 . 6}$ million American women would be "interested" in using a microbicidal product and approximately 7.7 million would be "very interested," even at a cost roughly twice that of a male condom. Another market study, conducted by Hillmark Consulting among urban women in 11 countries-Brazil, Egypt, France, India, Ivory Coast, Kenya, Philippines, Poland, South Africa, Thailand, and Venezuela-concluded that there is potentially a substantial commercial market for microbicides that is sufficient to justify further product development.

\section{Growing interest in microbicides}

Scientific and policy interest in microbicides has grown steadily, evidenced by some of the following key developments: 
- The International Working Group on Microbicides (IWGM), established in 1994, is comprised of major public agencies involved in microbicide funding, research, and development. It aims to facilitate the development, production, and distribution of microbicides, promotes sharing of research information, and provides technical expertise for the development of research guidelines.

- A 1997 symposium on Practical and Ethical Dilemmas in the Clinical Testing of Microbicides, cosponsored by the Population Council and Women's Health Advocates on Microbicides, brought together 55 scientists, activists, and ethicists from 15 countries to debate and build consensus on how to conduct microbicide clinical trials.

- The Alliance for Microbicide Development, a consortium of biopharmaceutical companies, research organisations, and advocacy groups, was founded in 1998. It catalyses diverse interests at work in the field, educates policymakers and the public, advocates for microbicide development, tracks and communicates progress, and aims to reduce disincentives and stimulate investment in microbicide research and development.

- An October 1998 meeting, organised by Family Health International, IWGM, the Consortium for Industrial Collaboration in Contraceptive Research, and CONRAD, reviewed opportunities for collaboration between industry and the public sector.

- A Global Campaign for Prevention Options for Women was launched in 1998 to increase public awareness, mobilise political will, and increase investment by the public sector and private donors. It now has more than 60 cosponsors worldwide with a secretariat at PATH (e-mail: globalcampaign@path-dc.org).

- In 1999, 2000, and 2001, Preclinical Evaluation Workshops, sponsored by the National Institute of Allergy 
and Infectious Diseases, National Institutes of Health $(\mathrm{NIH})$, assessed scientific progress and outstanding questions related to laboratory testing of microbicides.

- The first major international scientific conference, Microbicides 2000, held in March 2000 in Washington, DC, was attended by more than 650 participants from 40 countries.

While investment remains insufficient, there have recently been some encouraging steps forward in funding for microbicide research and development:

- The European Commission has increased funding for scientific and policy research, and in 2000 identified microbicides as a priority in its HIV/AIDS programme in developing countries, joining other European funders such as the Department for International Development (DfID) and the Swedish International Development Agency (SIDA).

- The National AIDS Research Institute in France recently established a microbicides working group, is funding a number of studies, and has expressed interest in increasing support for microbicide research and development.

- The Microbicides Development Act, under consideration by the US Congress, proposes a progressive increase in $\mathrm{NIH}$ investment in microbicides research and development from its current level of approximately $\$ 23$ million to reach $\$ 100$ million in 2003.

- Private funding in the USA has also increased in response to advocacy. For example, in 2000 the Gates Foundation provided a grant of $\$ 25$ million for product development and clinical trials, and in 1999 the American Foundation for AIDS Research launched a grant initiative to support innovative biomedical research on microbicides, joining other private foundations such as Rockefeller, Mellon, and Hewlett in supporting microbicides research. In 2001 the Ford Foundation committed \$1 million and the Goldman Foundation 
$\$ 500,000$ to support advocacy activities. There has also been initial interest and investment by venture capitalists.

\section{CHALLENGES TO BE ADDRESSED}

Building on recent advances to make a product available will require a significant increase in investment from both the public and private sectors to accelerate research and development. A major increase in funds should be accompanied by a strategic plan and clear criteria for how to best target these resources to advance the most promising products and overcome bottlenecks in the research and development process. Devising strategies to increase public support and to address barriers to industry involvement is crucial. Finally, it is critical to step up planning efforts to ensure future product availability and access.

\section{Increasing public-sector investment}

Because of the near absence of private-sector support from the pharmaceutical industry, the advances achieved in microbicide research and development have derived almost exclusively from public-sector investment. A number of government and intergovernmental agencies have supported microbicide work to varying degrees, including the European Union, UNAIDS (including funds from the governments of Germany and Belgium), WHO, national agencies such as the UK Medical Research Council, and bilateral donors such as SIDA and the UK DfID. It is estimated that the US public sector invested around \$32 million in 1999 (NIH \$26 million, CDC \$4 million, USAID \$2.3 million) in microbicide-related research. Globally the public sector provided less than \$40 million for microbicide research during 1999.

While this investment has been crucial, microbicides remain low on the agendas of most international and governmental funding bodies, and current levels of public investment 
are insufficient for the work that needs to be done. Among the urgent requirements are advancing the most promising products into and through the large-scale clinical trials needed to demonstrate effectiveness against HIV and other STIs, and supporting additional predinical work on new leads. The Alliance for Microbicide Development projects that an investment of $\$ 100$ million a year is required over the next five years to move this work forward. Although this represents substantial funding, it is relatively little compared with overall spending on AIDS research. For example, the US National Institutes of Health spent \$1.8 billion on AIDS research in 1999.

\section{Attracting private-sector investment}

To date, no major pharmaceutical company has made a significant investment in microbicide research and development $(R \& D)$; it is estimated that investment by the pharmaceutical industry is less than \$3 million. The UK Medical Research Council conducted an industry survey in 1995 in which none of the companies surveyed expressed interest in investing in microbicide research and development. The barriers cited included scientific uncertainty about the concept; perceptions of limited market and profit potential; competing demands for $R \& D$ resources; regulatory uncertainty; and concerns about safety and legal liability. A 1999 survey indicates that in the intervening years industry attitudes towards microbicides have generally become more positive, in response to developments in research and efforts to improve market information. In 1999, four of 30 companies surveyed expressed an interest in investing in research and development. The most critical barrier remains a lack of clear evidence about effectiveness_proof of the overall concept that a vaginal microbicide can prevent HIV and other STIs, as well as the efficacy of specific substances. An immediate priority must therefore be to conduct large-scale clinical trials of products to provide proof of concept, while at the same time working to address other industry concerns. 


\section{Markets and profitability}

Perceptions about potential markets and profitability are a significant barrier to private-sector investment in microbicides. Industry has generally assumed that the profitability of microbicides would be limited because the main market would be in developing countries, that women in these resource-poor settings would have limited willingness and ability to pay, and that there would be considerable pressure to distribute microbicides inexpensively. However, findings from the two major market studies conducted to date suggest that the developed-country market could be substantial and that women in low-income countries would be willing to pay for microbicides.

The aforementioned AGI survey concluded that there are potentially 7.7 million women in the US who would be "very interested" in a microbicide at a cost roughly twice that of a male condom. Even if the product were not $100 \%$ effective, the number of women "very interested" would still be around 4 million. In the EC market study, $25 \%$ of urban women surveyed in France thought a microbicide would be "very useful." The EC study also showed that women in developing countries would be prepared to pay a relatively high price to protect themselves from infection, especially when they think they are at high risk of acquiring HIV and other STIs. More than $60 \%$ of women surveyed in Ivory Coast and Kenya expressed willingness to pay up to five times the price of a male condom. The potential value of the market in urban Kenya for a microbicide that costs twice the price of a condom was estimated at \$3.8 million a year. In Brazil, potential annual sales could be worth $\$ 800$ million.

\section{Regulatory concerns}

Because microbicides represent a new product category, there is no clear precedent for establishing regulatory requirements for products at different stages of research and development, determining what level of effectiveness would be required for 
approval and introduction, and establishing what data are needed to support an application for product licensing. A related issue is uncertainty about prescribing and labelling information and possible caveats (for example, about use with condoms), which could have significant implications for product marketing and pricing.

These issues have been recognised and some steps are being taken towards resolving them. For example, the US Food and Drug Administration has established a Topical Microbicide Working Group that has made a commitment to priority review of products to prevent serious and life-threatening diseases, including microbicides for HIV prevention. The working group is also committed to advising applicants about the regulatory process, working to clarify preclinical requirements, and devising other fast-track mechanisms. These mechanisms and approaches are still new and their effectiveness in hel ping to bring a product to market has not been confirmed. However, a similar approach could be explored with regulatory agencies in Europe, using the centralised application procedure for European Union states of the European Medicines Evaluation Agency.

\section{Pricing and subsidy}

As with any new public health product category intended for the global market, microbicides also raise issues of intellectual property, pricing, and subsidy. It is critical to devise pricing mechanisms and purchase agreements to ensure that new products are available and affordable for the developing world and the public sector where they are needed most, while protecting intellectual property. Recent experience with HIV/AIDS vaccines demonstrates that innovative partnership arrangements can help reconcile industry's interest in profit with consumers' need for safe and affordable products.

\section{Liability}

Some industry executives have also expressed concern over potential risk of liability, including both litigation related to side 
effects and failure to protect against HIV and other STIs. While it is unclear whether liability is of equal concern for all companies and all markets, the topic warrants further examination.

\section{Challenges for ensuring availability, access, and use}

The acute need for microbicides in many developing countries makes it critical to take action now to identify and address constraints to availability and access. Many of these constraints, such as problems of cost, supply, logistics, distribution, quality assurance, and consumer information, echo experience with development and introduction of other drugs and technologies. Depending on the active ingredient, some microbicides may be restricted to prescription only until there is sufficient experience of use. However, devising ways to improve access by making microbicides available over the counter from the outset is essential if they are to have a significant impact on the HIV/AIDS epidemic. Ensuring access will include establishing and engaging innovative distribution networks, as well as traditional health service delivery points, pharmacies, and retail outlets.

These products will also need to be made available at an affordable price. International agencies and governments need to devise funding and distribution mechanisms to facilitate government procurement and subsidies. Pricing may also be influenced by taxes and tariffs on imported pharmaceutical products. This challenge could be addressed, in part, by building local manufacturing capacity, but the level of investment required and companies' willingness to invest require further examination.

Effective education strategies will be essential to ensure that both the public and individual consumers understand the concept and potential benefits of microbicides, their risks and limitations - particularly if a product is only partially effective-and their proper use. Regardless of the distribution channels, health professionals are likely to be important opinion leaders and must also be targeted for training and education about microbicides. 
There is considerable scope to learn from experience with existing prevention methods, other nonprescription products, and social marketing approaches. In addition, a growing body of research is beginning to examine ways to convey appropriate messages specifically about microbicides and their use.

\section{Scientific and research challenges}

Scientific knowledge about issues related to microbicides is developing rapidly but there are outstanding questions requiring research in basic, clinical, and social science. Additional resources are needed to accelerate ongoing work and to build capacity to address these research challenges, outlined below.

Critical issues in basic research include understanding mechanisms of transmission of HIV and other STIs during sexual intercourse, so that microbicide research can be targeted more effectively; expanding capacity for preclinical analysis of potential products; developing better animal models, including standardised assay methods to compare the potential efficacy of various candidate microbicidal compounds; generalising from efficacy in vitro and in animal models to clinical testing; and improving understanding about bioadhesion, retention, and distribution in the vagina, and about optimal formulations and dosages.

In clinical research the cost, complexity, and length of Phase II and III trials are key constraints. It is important to continue to explore new and innovative approaches to streamlining trials while maintaining the highest ethical standards. Trial sites must be in areas of high HIV incidence where there is a strong research infrastructure. This limits the number of potential sites and calls for efforts to identify and strengthen the capacity available at additional study sites. To meet ethical standards, participants must receive safer-sex counselling, condoms, and STI treatment; the optimum mix and approach to these services needs further exploration and refinement, and clearer guidelines for standards of services 
and care are needed. It is critical to use the limited resources available to test the most promising products, and developing criteria and a system to select products for testing is a priority, as is developing standardised outcomes for assessing safety and efficacy. More information is needed about the effect of other intravaginal products on microbicide safety and efficacy; the effect of microbicides on tests to diagnose STIs; the potential benefits of microbicides combined with barrier methods that protect the cervix; and possible side effects of long-term use and of use during pregnancy.

Behavioural research is needed to improve understanding about the determinants of product use and user effectiveness and to evaluate acceptability in parallel with product development. Existing acceptability studies indicate that multiple formulations are needed to meet women's different needs and preferences. Ongoing research related to product formulation and mode of delivery should be expanded to ensure the best chance of developing a successful product. In anticipation of product introduction, research about how women and couples understand, negotiate, and act on information regarding partial effectiveness and a hierarchy of prevention choices needs to be expanded.

Policy research is needed to establish the potential costeffectiveness and impact of microbicides in HIV prevention at different levels of use and efficacy, and to determine the potential impact of introducing microbicides on condom use. Additional information on the size and characteristics of the potential market is also critical to help stimulate investment and determine appropriate approaches to product introduction and distribution. Information to donors is essential to stimulate an expanded financial base for microbicide research.

\section{MOVING FORWARD: PRIORITIES FOR ACTION}

Despite the urgent need for microbicides and their scientific and public health promise, microbicides are a classic example 
of a product that will not reach the market without public-sector support. It is clear that the private sector alone will not take forward microbicide research and development and that current levels of public investment, while growing, are insufficient to accelerate and see through the process of bringing a product to market.

Given the limited availability of financial resources and limited number of clinical trial sites, it is critical that product development and testing be conducted efficiently to produce one or more products that are safe, effective, and available. The major stakeholders in microbicide research and development, including donors and scientists, need to collaborate to develop a scientific strategic plan and an agreed-upon set of criteria for determining which candidate products should be given priority for advancement. Building on this strategy and on existing initiatives, an appropriate mechanism and scientific review process are needed to raise and allocate greatly increased funding to specifically target bottlenecks in the R\&D process. For some public-sector and foundation donors, this will be critical to attracting or increasing their investment.

At the same time, strategies are needed to promote innovative public-private partnerships that encourage greater industry investment in microbicide research and development. Public-private partnerships have the potential to reduce the cost and risk to both sectors, provided that there are shared goals, a clear understanding of roles, and a balance between meeting the private-sector objective of seeking profitable venture and the public-sector goal of making affordable microbicides available in poorer countries and communities. A number of recent efforts, including the International AIDS Vaccine Initiative, the Medicines for Malaria Fund, the Global Alliance for TB Drug Development, and the Children's Vaccine Initiative, can provide valuable lessons.

International organisations, donor agencies, and governmental bodies can act as catalysts in three key areas: 
Increasing public investment and scientific interest in microbicides Increased and targeted public-sector investment is essential in order to accelerate $R \& D$, generate more interest in the scientific community, and support the research necessary to provide industry with evidence of effectiveness. Specific action is needed to:

- Increase awareness and commitment to microbicides within the international financial and development community, governments, and donor agencies, and encourage these public funding bodies to increase investment in microbicide research and development. This will require greatly expanded advocacy and, specifically, evidence of potential cost-effectiveness, analysis of current levels of funding and of investment required to move forward, and streamlined mechanisms to attract and disburse funds.

- Stimulate demand for increased investment in microbicides from developing-country policymakers, and from women's health groups, HIV/AIDS organisations, people living with HIV/AIDS, and potential consumers in developed and developing countries.

- Generate more interest and legitimacy within the scientific community and attract additional scientific talent to microbicide research and development, through increased funding, mechanisms to promote scientific collaboration and information exchange, and fast-track funding procedures.

- Generate additional and more flexible funding focused on product development, to follow up product leads and move promising candidates through large-scale clinical trials. Develop agreed-upon criteria for determining how available funding and trial sites should be prioritised.

- Provide support for identifying and strengthening the capacity of appropriate trial sites and building the necessary infrastructure with developing-country partners. 
- Encourage dialogue among public funding agencies, research institutions, and the biotechnology and pharmaceutical industry. The Eurovac project, which brings together research expertise and industry in Europe for vaccine development, offers a useful model.

\section{Stimulating industry investment in research and development}

Attracting industry investment in microbicide research and development will require efforts to improve and share market information, darify regulatory requirements and create a more supportive regulatory environment, and develop strategies to stimulate markets and reduce legal liability risks. Specific action is needed to:

- Accelerate clinical research to provide proof of conceptevidence to convince industry that microbicides can be effective against HIV and other STIs.

- Increase industry awareness of microbicides, including setting the stage for future private-sector production, delivery, and marketing.

- Create fast-track mechanisms for streamlining research, development, and commercialisation, including the use of orphan drug regulation.

- Provide information about potential markets in developing and developed countries, by taking into account both public and private demand.

- Explore new sources of investment, including venture capital concerns that specialise in pharmaceuticals.

- Establish public-sector mechanisms to provide incentives for industry and support market development through, for example, international market guarantees and bulk procurement. The World Bank, among other public-sector agencies, should take the lead in this area.

- Create supportive environments that stimulate research. For example, research on policy incentives led microbicide and HIV vaccine advocates to collaborate on introduction 
of tax credit legislation, under deliberation in the US Congress, to encourage companies, especially small companies, to stay in the field, and to attract new companies.

- Promote collaboration among scientists, regulatory bodies, industry, and researchers to define "acceptable" levels of effectiveness, recognising that the perfect product will never be available and that there will be successive generations of products.

- Develop internationally agreed-upon regulatory requirements for licensing different types of microbicide products and, for example, specifying conditions for over-the-counter products. Develop partnerships between regulators and associations representing industry, brokered by public agencies, to address regulatory, licensing, and related issues.

- Consider how existing mechanisms, such as Trade Related aspects of Intellectual Property, can be used to protect patents in developing countries, and draw on the experience of organisations such as the International AIDS Vaccine Initiative, which has been able to secure patent rights for developing-country applications for AIDS vaccine registration through innovative partnership agreements.

- Assess how existing mechanisms, such as medical injury compensation funds, could be used to reduce the risk of legal liability, a particular concern for companies likely to seek a market in the USA. Review other potential strategies for reducing the risk of litigation, including consumer education and counselling, clear and accurate labelling information, and postmarketing surveillance.

- Assess the likely costs and requirements of establishing manufacturing capacity, as well as the potential for technology transfer and developing-country production.

\section{Ensuring availability, access, and use}

Promoting action to plan for availability and accessibility-in particular, policy dialogue with decisionmakers-needs to 
happen well in advance of a product's being proven effective. Specific action is required to:

- Provide information to convince policymakers, in developed and developing countries, about the potential role of microbicides in preventing HIV and other STIs. This will include analysis of the potential cost-effectiveness and public health impact of microbicides with a range of characteristics, in a range of settings, and in comparison with and in combination with other preventive interventions.

- Promote dialogue with decisionmakers in developing countries and provide technical support to prepare national policy frameworks for microbicides introduction, promotion, and delivery, through health systems and as overthe-counter products.

- Consider potential strategies for promoting access and affordability-for example, advocacy with appropriate agencies to ensure microbicides are included in Essential Drugs Lists, bulk procurement, subsidies, incentives, and the potential of different financing mechanisms.

- Increase the involvement of international, bilateral, and technical agencies that could contribute to microbicide availability, access, and affordability, based on their areas of comparative advantage-for example, UNAIDS through its global leadership on HIV/AIDS, UNFPA through its mandate to support provision of essential reproductive health commodities, the World Bank through supporting pricing and financing mechanisms, and UNICEF through its focus on women and children and expertise in communication, community mobilisation, and product procurement and distribution.

- Develop appropriate strategies for product promotion, delivery, and marketing, and for educating health professionals and potential consumers. Explore the best ways to promote microbicides in the context of other prevention 
options and without undermining condom use. Conduct further behavioural research to improve understanding of protective behaviour in relationships, product preferences, and acceptability of microbicides to women and men.

- Build on the Global Campaign for STI/HIV Prevention Alternatives, involving a wider range of organisations in developing and developed countries in strategies to ensure microbicide availability and access-for example, social marketing organisations, women's groups, organisations working on HIV/AIDS and on sexual and reproductive health, development agencies, community organisations, and the media.

In 2000 the Rockefeller Foundation initiated a series of consultations intended to identify ways to accelerate microbicide research, development, and introduction. Dialogues have been held with leading scientific institutions, advocates, industry, donors, and other major stakeholder groups. These discussions have identified specific challenges and priorities facing the field, including insufficient capacity for multiple large-scale clinical trials, limited manufacturing capacity, regulatory uncertainty, and insufficient support for early stages of research on new compounds. The consultative process will seek ways to overcome these problems and explore new mechanisms to accelerate the development process.

\section{CONCLUSION}

Microbicides offer a critically important new means to enable women to protect themselves from HIV and other STIs with a method under their control. By meeting this need and widening the choice of prevention options, microbicides have the potential to exert a major impact on stemming the HIV/AIDS epidemic. This urgent public health need is supported by growing evidence and increasingly vocal demand for microbi- 
cides. Neglecting to make such products available would represent an international public health failure.

There is broadening scientific consensus that microbicides are feasible and a growing body of evidence about how best to approach research and product development. Transforming this promise into a safe, effective, and available product requires a range of initiatives to accelerate the science and increase investment. An urgent need is to provide proof of concept to demonstrate that microbicides can be effective, and advanced clinical trials to provide this evidence are of utmost priority.

The field faces a number of constraints, most notably inadequate funding and lack of industry participation. However, awareness of the potential of microbicides is increasing in the donor community, and there are indications that industry would be willing to play a more active role if given evidence of effectiveness and appropriate incentives. Much more can be done in this regard: developing a scientific strategy and criteria for prioritising products through the R\&D process, especially effectiveness trials; brokering negotiations among principal players from the public and private sectors; and developing innovative partnerships to address concerns about profitability and access. While an accelerated push must be made on research and development, it is critical to begin planning for product accessibility, introduction, and delivery. These efforts can benefit from careful evaluation of similar organizational initiatives created to stimulate research on vaccines and tropical diseases.

Making microbicides available as rapidly as possible will require accelerated scientific inquiry, global political commitment, concerted efforts to raise awareness about the potential of this approach, and a significant increase in investment from public agencies, private foundations, individuals, and industry. Targeting these resources efficiently will require close collaboration among scientists, researchers, technical agencies, 
donors, and advocates to create a strategic, product-oriented development plan.

Women worldwide urgently need safe, effective, and affordable microbicides to protect themselves from HIV and STIs. A strategic research and development approach is critical to achieving this fundamentally important goal. 


\section{Bibliography}

American Foundation for AIDS Research. 2000. Microbicides: a new weapon against HIV. AIDS Research Report, AmFAR.

Blanchard K, Coggins C, and Friedland B. 2000. Men's attitudes towards a potential vaginal microbicide in M exico, the United States and Zimbabwe. Reproductive Health M atters 8(15): 132-141.

Coggins C et al. 1998. A study of women's preferences regarding the formulation of over-the-counter vaginal spermicides. Population Council.

Darroch J and Frost J . 1999. Women's interest in vaginal microbicides. Family Planning Perspectives 31(1): 16-23.

de Zoysa I et al. 1998. Ethical challenges in efficacy trials of vaginal microbicides for HIV prevention. American J ournal of Public Health 88(4): 571-575.

Elias C and Coggins C. 1996. Female-controlled methods to prevent sexual transmission of HIV. AIDS 10: S43-51.

Elias C and Heise L. 1994. Challenges for the development of female-controlled vaginal microbicides. AIDS 8: 1-9.

Elias C and Heise L. 1993. The development of microbicides: a new method of HIV prevention for women. Working paper no. 6, International Programs Division, Population Council.

European Commission. 1999. A study into the market potential for vaginal microbicides. EU HIV/AIDS Programme in Developing Countries.

Family Health International. 1999. Microbicides/spermicides: opportunities for industrial collaboration. Summary of an international conference October 21-23 1998.

Fonn S and McGrory E. 1999. Informing research on HIV prevention: a consultation. Women's Health Project/Population Council.

Freestone D. 1997. Report of a survey of industrial interests, attitudes and perceptions of the development of vaginal virucides to prevent heter osexual transmission of HIV. Medical Research Council.

Harrison $\mathrm{P}$ et al. May 2000. Microbicide products database and summary. Silver Spring, MD: Alliance for Microbicide Development.

Hart $\mathrm{G}$ et al. 1999. Women's attitudes to condoms and femalecontrolled means of protection against HIV and STDs in south-western Uganda. AIDS Care 11(6): 687-698.

Heise L. 1998. Topical microbicides: talking points for advocates. Center for Health and Gender Equity.

Heise L et al. 1998. Practical and ethical dilemmas in the dinical testing of microbicides: a report on a symposium. CHANGE/IWHC/Population Council. 
Heise $L$ and Elias C. 1995. Transforming AIDS prevention to meet women's needs: a focus on developing countries. Social Science and Medicine 40(7): 931-943.

International Working Group on Vaginal Microbicides. 1996. Recommendations for the development of vaginal microbicides. AIDS 10: 1-6.

Stafford M et al. 1998. Safety study of nonoxynol-9 as a vaginal microbicide: evidence of adverse effects. J ournal of AIDS and Human Retrovirology 17: 327-331.

Stafford M et al. 1997. A placebo-controlled, double-blind prospective study in healthy female volunteers of dextrin sulphate gel: a novel potential intravaginal virucide. Journal of AIDS and Human Retrovirology 14: 213-218.

Stephenson J . 2000. Microbicides: ideas flourish, money to follow? J ournal of the A merican Medical Association 283(14): 1811-1812.

Stone A. 1997. Vaginal microbicides against HIV: current state of the art. International J ournal of Pharmaceutical M edicine 11: 81-83.

Stone A and Hitchcock P. 1994. Vaginal microbicides for preventing the sexual transmission of HIV. AIDS 8: S285-293.

UNAIDS. 1998. Microbicides for HIV prevention. UNAIDS Technical Update.

Van Damme L and Laga M. 1995. Report of EC meeting in vaginal microbicides: research issues. Institute of Tropical Medicine, Antwerp.

Van Damme $L$ and Rosenberg Z. 1999. Microbicides and barrier methods in HIV prevention. AIDS 13: S85-92.

van de Wijgert J et al. 1999. Men's attitudes toward vaginal microbicides and microbicide trials in Zimbabwe. International Family Planning Perspectives 25(1): 15-20.

Watts C et al. 1998. The impact of microbicides for HIV prevention: results of a mathematical modelling exercise. Presentation 12th World AIDS Conference, Geneva.

Weiss S and Louria D. 1994. Quo vadis: perinatal AIDS issues2004. Clinical Perinatology 21(1): 179-198.

Wulf $D$ et al. 1999. Microbicides: a new defense against sexually transmitted diseases. The Alan Guttmacher Institute. 
“M icrobicides offer a real possibility for hel ping women protect themselves from HIV/AIDS and other STIs. We need to invest far more resources and energy if we are to make this possibility a reality."

Peter Piot

Executive Director, J oint United Nations Programme on HIV/AIDS (UNAIDS)

"The development of safe, effective, and affordable microbicides is a priority for the European Commission. I am, therefore, pleased to be able to offer my support to The Case for Microbicides: A Global Priority. This document will play an important role in increasing awareness among policymakers of the potential of microbicides. It will also galvanise action to accelerate research and development and help ensure future availability to those most at risk in developing countries."

Lieve Fransen

Devel opment Directorate, European Commission

\section{(2) Population Council}

One Dag Hammarskjold Plaza New York, New York 10017 tel 001 212-339-0500 fax 001 212-755-6052 e-mail pubinfo@popcouncil.org www.popcouncil.org
TU International

Cityside House, First Floor 40 Adler Street London E1 1EE, United Kingdom tel 44 207-247-9944 fax 44 207-247-9224 www.ifh.org.uk 